\title{
Drug-resistant and hospital-associated Enterococcus faecium from wastewater, riverine estuary and anthropogenically impacted marine catchment basin
}

Ewa Sadowy ${ }^{1}$ and Aneta Luczkiewicz ${ }^{2 *}$

\begin{abstract}
Background: Enterococci, ubiquitous colonizers of humans and other animals, play an increasingly important role in health-care associated infections (HAls). It is believed that the recent evolution of two clinically relevant species, Enterococcus faecalis and Enterococcus faecium occurred in a big part in a hospital environment, leading to formation of high-risk enterococcal clonal complexes (HiRECCs), which combine multidrug resistance with increased pathogenicity and epidemicity. The aim of this study was to establish the species composition in wastewater, its marine recipient as well as a river estuary and to investigate the antimicrobial susceptibility of collected isolates. Molecular methods were additionally applied to test the presence of HiRRECC-related E. faecium.
\end{abstract}

Results: Two wastewater treatment plants (WWTPs), their marine outfalls and Vistula river that influence significantly the quality of waters in Gulf of Gdansk were sampled to investigate the presence of Enterococcus spp. Four-hundred-twenty-eight isolates were obtained, including E. faecium (244 isolates, 57.0\%), E. hirae (113 isolates, 26.4\%) and E. faecalis (63 isolates, 14.7\%); other species (E. gallinarum/casseliflavus, E. durans and E. avium) accounted for $1.9 \%$. Antimicrobial susceptibility testing revealed the presence of isolates resistant to erythromycin, tetracycline, amipicillin, fluoroquinolones and aminoglycosides (high-level resistance), especially among E. faecium, where such isolates were usually characterized by multilocus sequence types associated with nosocomial lineages 17, 18 and 78 of this species representing HiRECC, formerly called CC17. These isolates not only carried several resistance determinants but were also enriched in genes encoding pathogenicity factors (Esp, pili) and genes associated with mobile genetic elements (MGE), a feature also typical for nosocomial HiRECC.

Conclusions: Our data show that WWTPs constitute an important source of enterococcal strains carrying antimicrobial resistance determinants, often associated with the presence of MGE, for the recipient water environment, thus increasing a pool of such genes for other organisms. The presence of HiRECCs in wastewaters and marine/river environment may indicate that adaptations gained in hospitals may be also beneficial for survival of such clones in other settings. There is an obvious need to monitor the release and spread of such strains in order to elucidate better ways to curb their dissemination.

Keywords: WWTP, Marine waters, Enterococcus, Resistance, HiRECC, Plasmid, Replicon type, Toxin-antitoxin system, Esp, Pili

\footnotetext{
* Correspondence: ansob@pg.gda.pl

${ }^{2}$ Gdansk University of Technology, ul. G. Narutowicza 11/12, Gdansk 80-952,

Poland

Full list of author information is available at the end of the article
} 


\section{Background}

Enterococci are commensal bacteria of intestinal tract of mammals and birds, but these bacteria can also be found in the gut of reptiles and insects, and in different environmental compartments like soil and plants, in food (both as starters and contamination) as well as in aquatic ecosystems, both distributed with treated wastewater and lacking such anthropogenic impact [1]. In the human intestine, the Enterococcus faecalis and Enterococcus faecium are most abundant, and these two species are also most commonly isolated from human enterococcal infections, however, other species, such as Enterococcus avium, Enterococcus casseliflavus, Enterococcus durans, Enterococcus gallinarum, and Enterococcus raffinosus have also been detected [2,3]. Recently $E$. faecalis and E. faecium play more and more important role in hospital-acquired infections (HAIs), such as bacteremia, endocarditis, infections of urinary tract and post-surgery wounds [4], and nowadays represent a second etiologic agent of hospital bloodstream infections in Europe [5]. In the recent years, the relative proportion of E. faecium to E. faecalis is increasing in the US and Europe [6-8], which is likely due to the spread of a particular hospital-adapted polyclonal high-risk enterococcal complex (HiRECC) of E. faecium, initially described as clonal complex 17, $\mathrm{CC} 17$ [8]. This nosocomial subpopulation consists of three main lineages, named from the central sequence type (ST), defined by multilocus sequence typing (MLST), as lineages 17, 18 and 78 [9]. The acquisition of resistance to antimicrobials of several classes constitutes an important feature of hospital-associated E. faecium, what not only renders them resilient to therapy but also creates a reservoir of antimicrobial resistance genes, often associated with mobile genetic elements (MGE), such as conjugative transposons and plasmids [10]. The most important from the clinical point of view examples of acquired resistance among enterococci include resistance to (amino)penicillins, fluoroquinolones, glycopeptides (vancomycin-resistant enterococci, VRE) and high-level resistance to aminoglycosides (HLAR) [3]. Resistance to ampicillin, associated with the changes in penicillin binding protein 5 (PBP5) and resistance to quinolones, determined by point mutations in genes encoding bacterial gyrase and topoisomerase IV are characteristic phenotypic features of nosocomial E. faecium $[11,12]$. Such strains also commonly carry resistance genes to other classes of antimicrobials, such as tetracyclines $\{\operatorname{tet}(\mathrm{M})$, tet $(\mathrm{L}), \operatorname{tet}(\mathrm{S})$ and $\operatorname{tet}(\mathrm{O})\}$, macrolides $\{$ erm (B) $\}$ and aminoglycosides [13]. The HLAR phenotype is usually determined by the aac(6')-Ie-aph(2") gene, encoding a so-called bi-functional enzyme responsible for resistance to all aminoglycosides, except for streptomycin; high-level resistance to this compound is typically specified by ant (6')-Ia [3]. Hospital-associated E. faecium is also enriched in several virulence factors, such as enterococcal surface protein (Esp) and MSCRAMM proteins [14-16].

Several studies have addressed the spread of HiRECCs, especially VRE, within as well as among health-care facilities [17]. Much less is known, however, about the release of drug-resistant enterococci and HiRECCs into the environment, and their subsequent survival. Since it is suspected that human-associated bacteria can be regarded as vectors of gene transmission into environmental populations [18] and positive selection of bacteria resistant to antimicrobial agents was observed in wastewater processes $[19,20]$, the potential role of effluents from wastewater treatment plant (WWTP) in dissemination of clinically relevant bacteria and genes needs evaluation. It is particularly important in ecosystems subjected to strong anthropogenic impact, such as the Gulf of Gdansk and its shallow western part, the Puck Bay. Significant pollution load is discharged to this coastal area through the numerous local rivers and marine outfalls. Due to limited water exchange in the Gulf of Gdansk, safe wastewater disposal is essential to prevent the environmental degradation and to preserve the public health. Epidemiological studies reported a direct relationship between the risk of gastroenteritis among swimmers and density of enterococci in surface waters [21]. Additionally, resistant and multiresistant enterococci were detected in effluent of WWTPs $[18,20,22]$, suggesting their survival capacity in treatment processes. However, no microbiological standards have been set on WWTP effluents in the majority of European countries and it is required instead to monitor the quality of recreational water [23]. The US Environmental Protection Agency [21] as well as the European Union legislation [23] recommended detection of fecal enterococci, together with Escherichia coli as indicators of fecal contamination of bathing water.

Aim of the current study was to investigate the presence and species composition of enterococci in treated wastewater, river estuary water and their recipient, highly anthropogenically impacted Gulf of Gdansk. For this purpose, enterococci were isolated from wastewater of two local WWTPs, Gdansk-Wschod (influent - W-INF, effluent - W-EFF and bioreactor - W-BR) and GdyniaDebogorze (effluent - D-EFF) as well as from their marine outfalls (W-MOut and D-MOut, respectively). Additionally, the Vistula River mouth was sampled, due to ecological importance of this river flows for the Gulf of Gdansk area (Figure 1). Identification and further characterization of drug-resistant enterococci, especially the most prevalent E. faecium, including its resistance, virulence and MGE genes was in the special focus of the study, due to the problem posed by such clones for safe, economical and reliable way of wastewater disposal in costal ecosystems. 


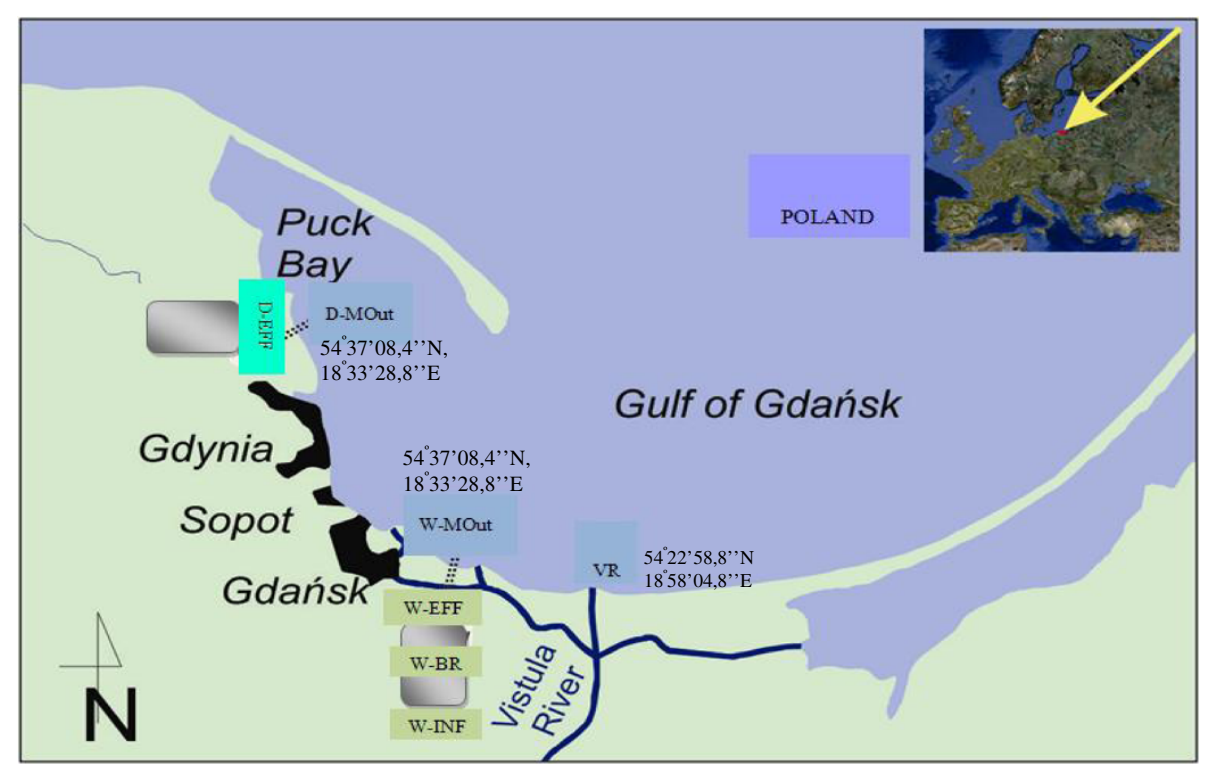

Figure 1 Sampling sites location: WWTP Gdansk-Wschod - influent (W-INF), bioreactor (W-BR), effluent (W-EFF) and marine outfall (W-MOut); WWTP Gdynia-Debogorze effluent (D-EFF) and marine outfall (D-MOut); Vistula River mouth (VR). Both WWTPs treat mainly municipal wastewater; industrial and not disinfected hospital wastewater consist approximately $10 \%$ and $0.2 \%$ of daily inflow, respectively. The WWTP Gdansk-Wschod works in a modified University of Cape Town system; Qav. = $96000 \mathrm{~m}^{3} / \mathrm{d}$; serves 570000 people; in operation since 2001 . The WWTP Gdynia-Debogorze works in Bardenpho system, including the Barnard modification; Qav. = 55000 m²/d; serves 350000 people; in operation since 2011. The Vistula River is the second biggest river (1 $048 \mathrm{~km} \mathrm{long)} \mathrm{in} \mathrm{the} \mathrm{catchment's} \mathrm{area} \mathrm{of} \mathrm{the} \mathrm{Baltic} \mathrm{Sea;} \mathrm{the} \mathrm{average} \mathrm{flow} \mathrm{at}$ the mouth to the Baltic Sea ca. $1050 \mathrm{~m}^{3} \cdot \mathrm{s}^{-1}$.

\section{Results}

\section{Species composition and antimicrobial susceptibility of} enterococcal isolates

In this study, the number of enterococci in WWTP effluents (W-EFF and D-EFF) remained high for both WWTP, yielding up to $6.1 \times 10^{5} \mathrm{CFU}$ per $100 \mathrm{~mL}$ (Table 1), although the WWTP Gdansk-Wschod showed over 99\% efficiency in the removal of enterococci. In marine outfalls of the two WWTPs (W-MOut, D-MOut) as well as at the Vistula
River mouth, enterococci were detected at low densities, i.e. below $100 \mathrm{CFU}$ per $100 \mathrm{~mL}$. Altogether, 428 isolates were collected, including 243 isolates from wastewater, 116 isolates from marine outfalls, and 69 from Vistula River mouth (Table 1). These 428 isolates were mainly identified as E. faecium (altogether 244 isolates, 57\%), Enterococcus hirae (113 isolates, 26.4\%) and E. faecalis (63 isolates, $14.7 \%)$, with an occasional occurrence of E. gallinarum/ casseliflavus, E. durans and E. avium (4, 3, and 1 isolates,

Table 1 Presence (CFU $100 \mathrm{~mL}^{-1}$ ) of enterococci, number (\%) of enterococcal isolates recovered and species composition at particular sites

\begin{tabular}{|c|c|c|c|c|c|c|c|c|c|}
\hline & & \multicolumn{6}{|c|}{ WWTP } & \multirow{3}{*}{$\begin{array}{c}\text { Vistula } \\
\text { river } \\
\text { VR }\end{array}$} & \multirow{3}{*}{ Total } \\
\hline & & \multicolumn{4}{|c|}{ Gdansk-Wschod } & \multicolumn{2}{|c|}{ Gdynia-Debogorze } & & \\
\hline & & W-INF & W-BR & W-EFF & W-MOut & D-EFF & D-MOut & & \\
\hline Presence & CFU $100 \mathrm{~mL}^{-1}$ & $(0.7-23) \times 10^{7}$ & na & $(0.1-6.1) \times 10^{5}$ & $3-60$ & $(0.8-3.1) \times 10^{5}$ & $2-80$ & $1-30$ & - \\
\hline \multicolumn{2}{|c|}{ Number (\%) of recovered isolates } & $33(7.7)$ & $55(12.8)$ & $82(19.2)$ & $45(10.5)$ & $73(17.1)$ & $71(16.6)$ & $69(16.1)$ & $428(100)$ \\
\hline \multirow{6}{*}{$\begin{array}{c}\text { Species composition: } \\
\text { number (\%) }\end{array}$} & E. faecium & $19(57.6)$ & $36(65.5)$ & $53(64.6)$ & $29(64.4)$ & $41(56.2)$ & $40(56.3)$ & $26(37.7)$ & $244(57)$ \\
\hline & E. faecalis & $5(15.2)$ & $8(14.5)$ & $19(23.2)$ & $4(8.9)$ & $19(26.0)$ & $3(4.3)$ & $5(7.2)$ & $63(14.7)$ \\
\hline & E. hirae & $8(24.2)$ & $11(20.0)$ & $7(8.5)$ & $11(24.4)$ & $12(16.4)$ & $27(38.0)$ & $37(53.6)$ & $113(26.4)$ \\
\hline & E.casseliflavus/gallinarum & $1(3.0)$ & nd & $2(2.5)$ & nd & $1(1.4)$ & nd & nd & $4(1.0)$ \\
\hline & E. durans & nd & nd & $1(1.2)$ & $1(2.3)$ & nd & $1(1.4)$ & nd & $3(0.7)$ \\
\hline & E. avium & nd & nd & nd & nd & nd & nd & $1(1.5)$ & $1(0.2)$ \\
\hline
\end{tabular}

na - not applicable, $n d$ - not detected.

Abbreviations of sampling points' locations and their description provided in Figure 1. 
respectively, altogether $1.9 \%)$. The most common species in all sampled sites was E. faecium (56.2\% - 65.5\%), with the exception of Vistula River mouth where $E$. hirae was predominant $(53.6 \%$ of isolates), followed by $E$. faecalis (37.7\%).

In the next step, antimicrobial susceptibility was tested for E. faecium and E. faecalis isolates (Table 2). It should be noted that at some points a low number of E. faecalis isolates was recovered (fewer than 10 isolates) and thus, certain resistance rates obtained for E. feacalis should be treated with caution. Resistance to erythromycin was detected with the highest prevalence among both species, however, rates of resistance to this compound varied over a broad range. Erythromycin-resistant E. faecium comprised $36.8 \%$ of isolates in raw wastewater (W-INF), $45.3 \%$ in treated wastewater (W-EFF) and $58.6 \%$ in marine outflow (W-MOut) of WWTP Gdansk-Wschod. Similar tendency was seen for E. faecalis isolates where resistance rates in the sampling points listed above were equal to $20.0 \%, 68.4 \%$ and $100 \%$, respectively. For WWTP Gdynia-Debogorze effluent (D-EFF) and marine outflow (D-MOut), erythromycin resistance rates for E. faecium varied between $68.2 \%$ and $55.0 \%$, respectively, while for $E$. faecalis were equal $68.4 \%$ and $66.7 \%$, respectively. In the case of fluoroquinolones, resistance to ciprofloxacin among
E. faecium varied between $30.8 \%$ in Vistula River mouth to $44.8 \%$ in W-MOut, while resistance to levofloxacin did not exceed 20\%. Among E. faecalis resistance to ciprofloxacin and levofloxacin was, in general lower then reported for $E$. faecium in the corresponding sampling points (up to 25.0\%), except Vistula River mouth. The high-level streptomycin resistance (HLSR) was prevalent and reached 20.7\% for E. faecium isolates from marine outflow of WWTP Gdansk-Wschod (W-MOut). Also for E. faecalis, HLSR phenotype was detected among up to $16 \%$ of all tested isolates. Resistance to glycopeptides, linezolid and daptomycin was not detected among all tested enterococci.

\section{Clonal structure of E. faecium isolates, and distribution of virulence, resistance and MGE genes}

Sixty-nine isolates of E. faecium (28.3\% of all isolates of this species) were further subjected to MLST and analysis of the presence of resistance, virulence and MGE genes. These isolates presented various phenotypes of resistance to antimicrobial compounds, as described below, and were obtained mostly from effluents and marine outfalls of both WWTPs (Table 3). MLST discerned 54 different STs (Figure 2), including 23 new ones (STs 632-654). The comparative eBURST analysis against the whole MLST E. faecium database (as of the $5^{\text {th }}$ April 2013)

Table 2 Antimicrobial resistance of E. faecium and E. faecalis

\begin{tabular}{|c|c|c|c|c|c|c|c|c|c|c|}
\hline & \multicolumn{10}{|c|}{ Number (\%) of isolates } \\
\hline & \multicolumn{8}{|c|}{ Resistant to a single antimicrobial agent } & \multirow{2}{*}{$\begin{array}{c}\text { Sensitive } \\
\mathrm{S}\end{array}$} & \multirow{2}{*}{$\begin{array}{c}\text { MDR } \\
\text { phenotype }\end{array}$} \\
\hline & GM & ST & AM & CIP & LVX & TE & SYN & $\mathrm{E}$ & & \\
\hline \multicolumn{11}{|c|}{ E. faecium $n=244$} \\
\hline$W=\operatorname{INF}(n=19)$ & $1(5.3)$ & $3(15.8)$ & $1(5.3)$ & $6(31.6)$ & $1(5.3)$ & $5(26.3)$ & $6(31.6)$ & $7(36.8)$ & $6(31.6)$ & $4(21.1)$ \\
\hline$W-B R(n=36)$ & $1(2.8)$ & $2(5.6)$ & $1(2.8)$ & $12(33.2)$ & $3(8.3)$ & $7(19.4)$ & $19(52.8)$ & $16(44.4)$ & $10(27.8)$ & $8(22.2)$ \\
\hline W-EFF $(n=53)$ & $3(5.7)$ & $2(3.8)$ & $4(7.5)$ & $23(43.4)$ & $10(18.9)$ & $10(18.9)$ & $18(34.0)$ & $24(45.3)$ & $12(22.6)$ & $14(26.4)$ \\
\hline W-MOut $(n=29)$ & 0 & $6(20.7)$ & $6(20.7)$ & $13(44.8)$ & $4(13.8)$ & $8(27.6)$ & $14(48.3)$ & 17 (58.6) & $5(17.4)$ & $9(31.0)$ \\
\hline D-EFF $(n=41)$ & $1(2.4)$ & $6(14.6)$ & $5(12.2)$ & $13(31.7)$ & $2(4.9)$ & $10(24.4)$ & $12(29.2)$ & $28(68.2)$ & $4(9.8)$ & $8(19.5)$ \\
\hline D-MOut $(n=40)$ & $1(2.5)$ & $2(5)$ & $2(5)$ & $14(35.0)$ & $3(7.5)$ & $2(5.0)$ & $21(52.5)$ & $22(55.0)$ & $7(17.5)$ & $3(7.5)$ \\
\hline$V R(n=26)$ & 0 & $1(3.8)$ & 0 & $8(30.8)$ & $1(3.8)$ & $2(7.7)$ & $15(57.7)$ & $11(42.4)$ & $3(11.5)$ & $3(11.5)$ \\
\hline All $(n=244)$ & $7(2.9)$ & $22(9.0)$ & $19(7.8)$ & $90(36.9)$ & $24(9.8)$ & $44(18.0)$ & $105(43.0)$ & $125(51.2)$ & $49(20.1)$ & $47(19.3)$ \\
\hline \multicolumn{11}{|c|}{ E. faecalis $n=63$} \\
\hline W-INF $(n=5)$ & 0 & $1(20.0)$ & 0 & $1(20.0)$ & 0 & $1(20.0)$ & na & $1(20.0)$ & $4(80.0)$ & 0 \\
\hline W-BR $(n=8)$ & $2(25.0)$ & $2(25.0)$ & $1(12.5)$ & $2(25.0)$ & $2(25.0)$ & $2(25.0)$ & na & $7(87.5)$ & $1(12.5)$ & $2(25.0)$ \\
\hline W-EFF $(n=19)$ & 0 & $1(5.3)$ & $1(5.3)$ & $3(15.8)$ & $3(15.8)$ & $4(21.1)$ & na & $13(68.4)$ & 0 & $3(15.8)$ \\
\hline W-MOut $(n=4)$ & 0 & 0 & 0 & 0 & 0 & 0 & na & $4(100)$ & 0 & 0 \\
\hline D-EFF $(n=19)$ & $2(10.5)$ & $5(26.3)$ & 0 & $1(5.3)$ & 0 & $9(47.4)$ & na & $13(68.4)$ & $4(21.1)$ & $5(26.3)$ \\
\hline D-MOut $(n=3)$ & $1(33.3)$ & $1(33.3)$ & 0 & 0 & 0 & $2(66.7)$ & na & $2(66.7)$ & 0 & $1(33.3)$ \\
\hline $\operatorname{VR}(n=5)$ & 0 & 0 & 0 & $2(40.0)$ & 0 & 0 & na & $1(20.0)$ & $2(40.0)$ & 0 \\
\hline All $(n=63)$ & $5(7.9)$ & 10 (15.9) & $2(3.2)$ & $9(14.3)$ & $5(7.9)$ & 18 (28.6) & na & $41(65.1)$ & $11(17.5)$ & $11(17.5)$ \\
\hline
\end{tabular}

GM, gentamicin; ST, streptomycin; AM, ampicillin; CIP, ciprofloxacin; LVX, levofloxacin; TE, tetracycline; SYN, quinupristin-dalfopristin; E, erythromycin; S, sensitive to all tested antimicrobial agents; MDR, multiple drug resistance; na, not applicable. Abbreviations of sampling points' locations and their description provided in Figure 1. 
Table 3 Distribution of virulence genes and resistance determinants among lineages, CCs and STs of $E$. faecium

\begin{tabular}{|c|c|c|c|c|c|c|c|c|c|c|c|c|c|c|}
\hline \multirow{2}{*}{$\begin{array}{l}\text { Lineage/ } \\
\text { CC/ST }\end{array}$} & \multirow[t]{2}{*}{ MT } & \multirow{2}{*}{$\begin{array}{l}\text { Isolation } \\
\text { site }\end{array}$} & \multicolumn{5}{|c|}{ Virulence genes } & \multicolumn{7}{|c|}{ Resistance determinants } \\
\hline & & & $\begin{array}{l}\text { esp/ } \\
\text { intA }\end{array}$ & fms5 & fms17 & fms19 & fms21 & $p b p 5$ & GyrA & ParC & $\begin{array}{c}\operatorname{aac}\left(6^{\prime}\right)- \\
\text { le-aph(2") }\end{array}$ & $\begin{array}{c}\text { ant } \\
\left(6^{\prime}\right)-l a\end{array}$ & $\begin{array}{l}\text { tet } \\
\text { (M) }\end{array}$ & $\begin{array}{l}\text { tet } \\
\text { (L) }\end{array}$ \\
\hline \multicolumn{15}{|c|}{ Lineage 17} \\
\hline $17(2)$ & 1,8 & W-EFF & 2 & 2 & 2 & 2 & 2 & $\begin{array}{c}p b p 5- \\
30\end{array}$ & S84R & $\begin{array}{l}\text { R61G } \\
\text { S80R }\end{array}$ & & & 1 & 1 \\
\hline 386 & 7 & W-MOut & 1 & 1 & 1 & 1 & 1 & & & & & 1 & & \\
\hline \multicolumn{15}{|c|}{ Lineage 18} \\
\hline $18(3)$ & $\begin{array}{l}1 \\
\text { (3) }\end{array}$ & $\begin{array}{l}\text { D-EFF, } \\
\text { W-MOut }\end{array}$ & & 3 & 3 & 3 & 1 & $\begin{array}{c}p b p 5- \\
20\end{array}$ & S84Y & $\begin{array}{l}\text { R61G } \\
\text { S801 }\end{array}$ & 1 & 2 & 3 & 3 \\
\hline 262 & 10 & W-EFF & & 1 & 1 & & 1 & $\begin{array}{c}p b p 5- \\
25\end{array}$ & S84Y & R61G & 1 & & 1 & 1 \\
\hline 574 & 402 & $V R$ & & 1 & & & 1 & & & & & & & \\
\hline \multicolumn{15}{|c|}{ Lineage 78} \\
\hline $78(4)$ & $\begin{array}{l}159 \\
(4)\end{array}$ & $\begin{array}{l}\text { W-EFF, } \\
\text { W-MOut }\end{array}$ & 4 & 4 & 4 & 4 & 4 & $\begin{array}{c}p b p 5- \\
28\end{array}$ & $\begin{array}{c}584 R / \\
Y\end{array}$ & $\begin{array}{l}\text { R61G } \\
\text { S80R }\end{array}$ & 2 & 1 & 2 & 2 \\
\hline $266(2)$ & $\begin{array}{l}139 \\
(2)\end{array}$ & $\begin{array}{l}\text { W-INF, } \\
\text { D-EFF }\end{array}$ & & 2 & 1 & 2 & 2 & $\begin{array}{c}p b p 5- \\
24\end{array}$ & & & & 1 & 1 & \\
\hline 323 & 12 & D-MOut & & 1 & 1 & 1 & 1 & $\begin{array}{l}p b p 5- \\
26\end{array}$ & $w t$ & $\begin{array}{l}\text { R61G } \\
\text { S80l }\end{array}$ & 1 & 1 & 1 & 1 \\
\hline 564 & 302 & D-EFF & 1 & 1 & 1 & & 1 & $\begin{array}{c}p b p 5- \\
29\end{array}$ & S84I & $\begin{array}{l}\text { R61G } \\
\text { S80R }\end{array}$ & & 1 & & \\
\hline 653 & 302 & W-EFF & & & & & 1 & nd & S84I & $\begin{array}{l}\text { R61G } \\
\text { S80R }\end{array}$ & & 1 & & \\
\hline \multicolumn{15}{|l|}{ CC5 } \\
\hline $29(2)$ & & $\begin{array}{l}\text { W-EFF, } \\
\text { W-MOut }\end{array}$ & & 2 & 1 & & 1 & & & & & & & \\
\hline 66 & & W-MOut & & 1 & 1 & & 1 & & & & & & 1 & 1 \\
\hline 97 & & W-EFF & & & & & 1 & & $w t$ & $\begin{array}{l}\text { R61G } \\
\text { S80R }\end{array}$ & & & & \\
\hline 123 & & W-EFF & & 1 & & 1 & & & $w t$ & R61G & & & & \\
\hline 148 & & W-MOut & & 1 & & & & $\begin{array}{c}p b p 5- \\
30\end{array}$ & $w t$ & $\begin{array}{l}\text { R61G } \\
\text { S80R }\end{array}$ & & 1 & 1 & 1 \\
\hline 168 & & W-MOut & & 1 & 1 & & & $\begin{array}{c}p b p 5- \\
31\end{array}$ & & & & 1 & 1 & 1 \\
\hline 505 & & W-EFF & & 1 & & & & & $w t$ & R61G & & & & \\
\hline 588 & & D-MOut & & 1 & & & & $\begin{array}{c}p b p 5- \\
30\end{array}$ & & & & 1 & 1 & 1 \\
\hline
\end{tabular}
Transposon pIP501 PRE25 PRUM PEF418 pLG1 pMG1 txe $-\zeta$ 
Table 3 Distribution of virulence genes and resistance determinants among lineages, CCs and STs of E. faecium (Continued)

\begin{tabular}{|c|c|c|c|c|c|c|c|c|}
\hline 635 & D-EFF & & 1 & & 1 & & & \\
\hline 636 & W-EFF & 1 & & & & & $w t$ & R61G \\
\hline 637 & W-EFF & 1 & 1 & & 1 & & $w t$ & R61G \\
\hline 638 & W-EFF & & 1 & & & & $w t$ & $\begin{array}{l}\text { R61G } \\
\text { S801 }\end{array}$ \\
\hline 642 & W-EFF & 1 & 1 & 1 & & & & \\
\hline 645 & D-EFF & 1 & 1 & & & & & \\
\hline 646 & W-EFF & 1 & 1 & & & & & \\
\hline 649 & W-BR & 1 & 1 & 1 & & $\begin{array}{c}p b p 5- \\
32\end{array}$ & $w t$ & R61G \\
\hline $650(3)$ & D-EFF & 3 & 3 & & & $\begin{array}{c}p b p 5- \\
27\end{array}$ & & \\
\hline
\end{tabular}

CC 22

$21 \quad$ W-EFF

22 W-EFF

$25 \quad$ W-EFF

32 (3) W-EFF

$92 \quad$ W-EFF

441 W-EFF

533 W-EFF

$633 \quad$ W-EFF

644 D-EFF

CC27

652 W-EFF

CC46

$47 \quad$ VR

69 D-EFF

CC94

94 W-MOut

361 (4) D-EFF,

D-MOut

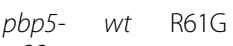

-EFF

W-EFF

-EFF

$R$

D-EFF


Table 3 Distribution of virulence genes and resistance determinants among lineages, CCs and STs of E. faecium (Continued)

\begin{tabular}{|c|c|c|c|c|c|c|c|c|c|c|c|c|c|c|c|c|c|c|c|c|c|c|}
\hline \multicolumn{23}{|l|}{ CC296 } \\
\hline 296 & W-EFF & & 1 & & 1 & & & & & & & & & & & & & & & & & \\
\hline \multicolumn{23}{|l|}{ CC639 } \\
\hline 639 & W-EFF & & 1 & 1 & & 1 & & & & & & & & 1 & & & & 1 & & & & \\
\hline \multicolumn{23}{|l|}{ CC648 } \\
\hline 634 & W-EFF & & 1 & & & 1 & & & & & & & & 1 & & & & 1 & & & & 1 \\
\hline 648 & W-EFF & & 1 & 1 & & 1 & & & & & & & & 1 & & & & 1 & & & & \\
\hline \multicolumn{23}{|c|}{ Doubletons } \\
\hline 632 & W-MOut & & 1 & & & 1 & & & & & & & & & & & & 1 & & & & \\
\hline \multicolumn{23}{|c|}{ Singletons } \\
\hline 264 & W-INF & & 1 & & 1 & 1 & & & & & & & & 1 & 1 & & & 1 & & & 1 & \\
\hline 641 & D-EFF & & 1 & 1 & & 1 & & & & & & & & & & & & 1 & & & & \\
\hline 643 & W-EFF & & 1 & & & 1 & & & & & & & & 1 & 1 & & & 1 & & & 1 & \\
\hline 647 & W-MOut & & & & 1 & 1 & & & & & & & & 1 & & & & 1 & 1 & & & \\
\hline 651 & D-EFF & & & 1 & 1 & 1 & & & & & & & & & 1 & & & 1 & & & & 1 \\
\hline 654 & VR & & & & 1 & 1 & & & & & & & & 1 & 1 & & & 1 & & & & 1 \\
\hline All (69) & & 8 & 57 & 49 & 29 & 46 & 6 & 17 & 20 & 17 & 1 & 9 & 4 & 39 & 27 & 14 & 7 & 55 & 2 & 12 & 10 & 5 \\
\hline
\end{tabular}

CC, clonal complex; ST, sequence type; MT, MLVA-type; $n d$, not determined due to lack of amplification of the $p b p 5$ gene; wt, wild-type; STs associated with MDR phenotype in bold. Abbreviations of sampling points' locations and their description provided in Figure 1. 


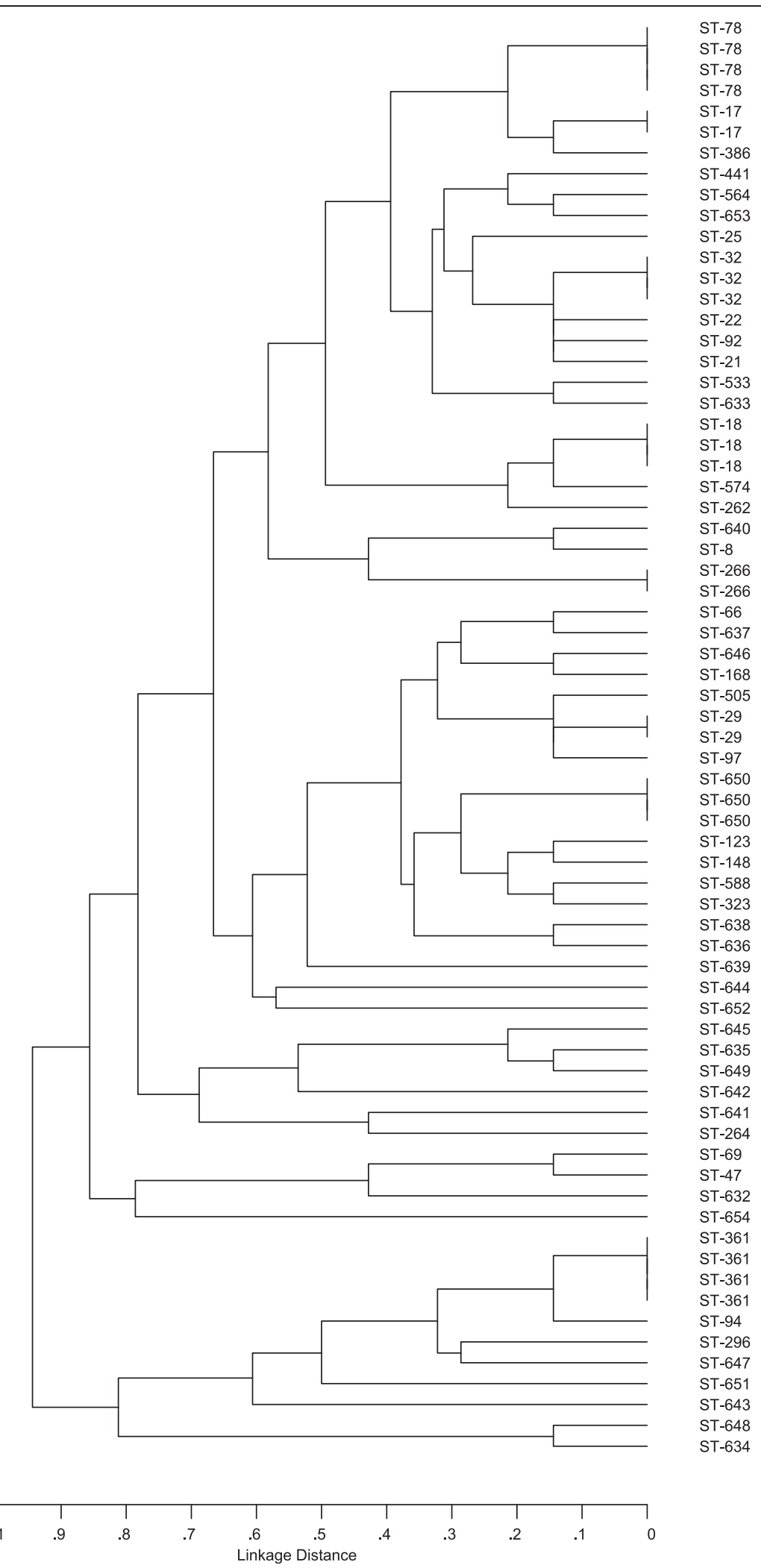

Figure 2 MLST-based similarity tree of E. faecium isolates, constructed using the START software and the UPGMA clustering algorithm. 
grouped the $38 \mathrm{STs}$, specific for 50 isolates into the major 'super-complex 17', characteristic for this species (data not shown). Further detailed analysis of the localization of particular STs within this structure revealed that 11 STs characteristic for 17 isolates belonged to the nosocomial complex of E. faecium, representing all three major lineages 17, 18 and 78 of a former CC17, as defined by Willems et al. [9] (Table 3). Seventeen STs (20 isolates), nine STs (11 isolates) and two STs with single isolates each belonged to $\mathrm{CC} 5, \mathrm{CC} 22$ and $\mathrm{CC} 9$, respectively, as defined by Freitas et al. [24]. Of the remaining 16 STs, nine were included into six small CCs (CCs 27, 46, 94, 296, 639, 648), unlinked to the major 'super-complex'; ST632 formed a 'doubleton' (i.e. was linked by a single-locus variant link to only one ST from the database) and six STs, represented by single isolates, were singletons, i.e. were not related to any ST in the database at the time of analysis. Thirty isolates (43.5\%) in the investigated group showed the MDR phenotype, which was significantly associated $(p=0.00006)$ with isolates from the nosocomial complex (Table 3 and Figure 3) but found also in CC5, CC22 and CC94; this phenotype did not occur among small CCs or singletons. Seventeen isolates, representing the nosocomial complex were additionally studied by multilocus VNTR (variable number tandem repeats) analysis (MLVA) to better elucidate the relationships among these isolates. Altogether, nine MLVA-types (MTs) were found (Table 3). Importantly, the same MLVA-type, MT159 associated with ST78 was characteristic for isolates derived from samples from W-EFF and W-MOut, suggesting survival of this particular clone.
IS16 was present in all 17 isolates included by MLST to three lineages of nosocomial $E$. faecium and this marker was limited to this group (Table 3 and Figure 3). The $e s p_{\text {Efm }}$ gene occurred always together with int $A$ among all isolates of lineage 17 and in some isolates of lineage 78 . The fms 19 pilin gene, detected in 29 isolates, was overrepresented among STs typical for nosocomial E. faecium while other pilin genes, such as fms5, fms 17 and fms 21 , detected in 57, 49 and 46 isolates, respectively, occurred among various CCs and singleton STs. Ampicillin resistance, significantly associated with isolates of nosocomial complex (10 of 17 isolates, $58.8 \%$; $\mathrm{p}=0.001$ ), occurred also in CC5 (6 isolates), CC22 and CC94 (1 isolate each). Sequencing of the 3 ' part of the pbp5 gene revealed its 11 nucleotide alleles corresponding to 11 variants of the $C$ terminal part of PBP5. Six alleles of the gene were new (pbp5-24 to $p b p 5-29)$, two alleles ( $p b p 5-20, p b p 5-22)$ were described previously among Polish hospital VREm isolates [13] and three alleles were found in other studies: $p b p 5-30$ occurred in a Portuguese animal strain of E. faecium [25] and pbp5-31 and pbp5-32 in clinical isolates TCGE70411_2 and 164306 also from Portugal (deposited as JN208888 and JN208885 in the GenBank, respectively). For a single ampicillin-resistant isolate of ST653 (lineage 78), pbp5 amplification was not achieved despite repeated attempts. The majority (11 of 17 isolates, $64.7 \%$ ) of isolates belonging to three lineages of nosocomial E. faecium showed resistance to ciprofloxacin determined by mutations R61G and S80I/R in ParC and $\mathrm{S} 84 \mathrm{I} / \mathrm{R} / \mathrm{Y}$ in GyrA. Ciprofloxacin resistance was also significantly over-represented among isolates of STs typical for nosocomial E. faecium ( $\mathrm{p}=0.0006)$. Nine

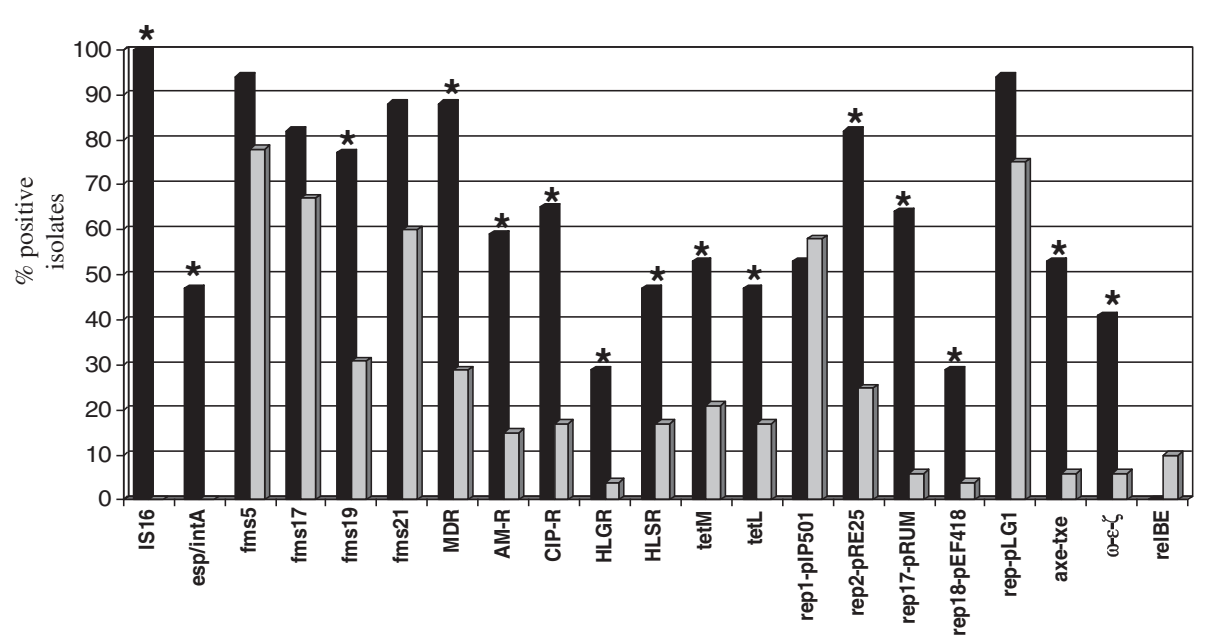

Figure 3 Distribution (\%) of IS16, resistance phenotypes and virulence, resistance and plasmid genes among $E$. faecium isolates. Black columns, isolates with STs typical for nosocomial E. faecium, grey columns, other E. faecium isolates. Significant differences ( $p<0.05$ ) between two groups are indicated by an asterisk. MDR, multi-drug resistance; AM-R, ampicillin resistance; CIP-R, ciprofloxacin resistance; HLGR, high-level gentamicin resistance; HLSR, high-level streptomycin resistance. 
isolates resistant to ciprofloxacin were found also in CCs 5, 9 and 22. These isolates possessed mutations in ParC mentioned above but had the wild-type QRDR in GyrA. HLGR occurred in five isolates of lineages 18 and 78 , and in single isolates of CC5 and CC22; this phenotype was determined by the presence of $a a c\left(6^{\prime}\right)-I e-a p h$ $(2 ")$ with an exception of an isolate from CC5 which was negative for this gene. High-level resistance to streptomycin (HLSR) was widely distributed among studied isolates, and determined by the ant $\left(6^{\prime}\right)$-Ia gene. Tetracycline resistance was found also in various STs; the major determinant of this phenotype was tet $(\mathrm{M})(20$ isolates), followed by tet $(\mathrm{L})$ (17 isolates). These two genes occurred together in 16 isolates. A single isolate of ST633, belonging to $\mathrm{CC} 22$, harbored tet(S). The tet (O) gene was absent in the studied group. For a single tetracycline-resistant isolate of ST17 none of the four tetracycline determinants studied was detected. Nine isolates carried int of Tn916, and four the $t n d X$ gene of Tn5397. These transposon-specific genes were not characteristic for any lineage or complex (Table 3). Plasmidreplication genes such as rep $2_{\mathrm{pRE} 25}$, rep $17_{\mathrm{pRUM}}$ and rep $18{ }_{\text {pEF418 }}$ (26, 14 and 7 isolates, respectively), and genes specifying toxin-antitoxin systems (TAS), axe-txe and $\omega-\varepsilon-\zeta$ (12 and 10 isolates, respectively) were significantly associated with the group of isolates of nosocomial E. faecium. Two other rep genes $\left(r e p 1_{\mathrm{pIP501}}, r e p_{\mathrm{pLG1}}\right)$ were widely distributed among all studied $E$. faecium isolates and the $r e p_{\mathrm{pMG} 1}$ gene occurred in two isolates (in a single isolate of ST533 from CC22 and in a singleton ST647). All $\omega-\varepsilon-\zeta$-positive isolates carried $r e p 2_{\mathrm{pRE} 25}$, and nine isolates showed a concomitant presence of axe-txe and rep17 $7_{\mathrm{pRUM}}$. The relBE genes were found solely among five nonnosocomial $E$. faecium (a difference in distribution without statistical significance, $\mathrm{p}=0.43$ ), among various $\mathrm{STs}$.

\section{Discussion}

In this study, Enterococcus spp. was used to evaluate the impact posed by treated wastewater of two local WWTPs on their receiver, the costal waters of Gulf of Gdansk. Total counts of enterococci observed for raw (W-INF) and treated (W-EFF, D-EFF) wastewater are consistent with our previous study, showing similar, over $99 \%$ reduction capacity of applied treatment processes. It is also reported in the literature that wastewater treatment processes based on activated sludge, although they focus on removal of nutrients and organic matter, simultaneously reduce faecal indicators with high efficiency, reaching up to $99.9 \%[18,22]$. Due to the high number of enterococci in raw wastewater, they are nevertheless released from a WWTP in a number up to $6.1 \times 10^{5} \mathrm{CFU}$ per $100 \mathrm{~mL}$. Thus, marine water sampled in the area directly impacted by treated wastewater (W-MOut and D-MOut) showed a higher number of enterococci than the one observed in
Vistula River mouth, however, lower by four orders of magnitude in comparison to corresponding treated wastewater (W-EFF and D-EFF). It should be noted that in marine outfalls (W-MOut, D-MOut) as well as in Vistula River mouth enterococci were detected in number lower than $100 \mathrm{CFU}$ per $100 \mathrm{~mL}$, i.e. the value set out by New Bathing Water Directive 2006/7/EC for the costal water of "excellent quality" [23].

It is suggested that enterococcal species composition in faecal-impacted environment depends from the source of contamination. In this study, two species most commonly colonizing humans, E. faecalis and E. faecium comprised together from $73 \%$ to $88 \%$ of enterococcal isolates in tested wastewater samples (W-INF, W-BR, W-EFF and D$\mathrm{EFF}$ ), $73 \%$ and $61 \%$ in marine outflows (W-MOut and DMOut, respectively) and $45 \%$ in the Vistula River mouth. The predominant species in wastewater and marine water impacted by treated wastewater was E. faecium (from 56 to $65 \%$ ), which stayed at a similar level during treatment processes, as determined also in our previous study [20]. Species distribution in wastewater samples is not well understood, and affecting factors may include differences in diet, climate, season and methods of detection. E. feacalis was found to be the most prevalent species in wastewater samples in Sweden [26], E. faecium in Spain, UK, Canada, France and Switzerland [26-29], while E. hirae predominated in Portugal and United States [22,30]. Although $E$. faecalis is typically the most abundant colonizer of humans in the community (e.g. [26,31]), E. faecium is generally most often associated with human microbial contamination [27,29]. E. faecalis was reported from agriculture-impacted waters [32] and E. hirae likely originates mainly from cattle and pig faecal contamination [26], which explains high relative proportion of these two species in Vistula River mouth. Apart from the variability of contamination sources, proportion of particular species may differ due to the differences of ability to sustain environmental stresses. In this study, enterococcal composition might have been influenced by wastewater treatment processes and marine water characteristics.

The effect of wastewater treatment and marine environment was seen on phenotypes of antimicrobial resistance. The positive selection of bacteria with resistance patterns has been already suggested and noted in wastewater processes $[19,20,22]$. In this study, the resistance rates to ampicillin, ciprofloxacin, levofloxacin and erythromycin, noted for E. faecium from raw wastewater (W-INF) were lower than these observed for this species in the corresponding treated wastewater (W-EFF), however, not statistically significant ( $p>0.05)$. Moreover, resistance rates to ampicillin, ciprofloxacin, tetracycline and erythromycin observed in marine outflow of WWTP Gdansk-Wschod (W-MOut) were higher than in treated wastewater of this plant. Such phenomenon was not observed for treated 
wastewater of WWTP Gdynia-Debogorze (D-EFF) and its marine outfall (D-MOut). Resistance rates among $E$. faecium originating from D-MOut were, in general, comparable to these detected in the Vistula River mouth. It should be noted that treated wastewater from WWTP Gdansk-Wschod has been discharged via marine outfall (W-MOut) for last 12 years while marine outfall of WWTP Gdynia-Debogorze (D-MOut) has been operating for last two years. The observed differences in resistance rate corresponding to the local impact caused by long and short-term operated marine outfalls (W-MOut and D-MOut) need further attention.

Significant rates of antimicrobial resistance, observed for isolates of E. faecalis from wastewater and marine/ river waters, impacted by wastewater, are in agreement with a recent study performed in six European countries, showing that in Poland the rates of resistance for human isolates of this species were usually among the highest, both in the community and hospitals [33]. To our knowledge, no corresponding data are available for E. faecium colonization in the community in Poland but a study focused on hospital VRE isolates showed their ubiquitous MDR phenotype and a high load of resistance genes [13]. In our study no vancomycin resistance were detected, likely due to relatively low (below 10\%) prevalence of VRE in Polish hospitals [5], although such isolates are isolated from the environment in other countries e.g., [34].

This study shows that hospital clones of E. faecium are important carriers of resistance genes in wastewaters. Most likely, in a significant part they originated from hospital wastewater treated together with communal wastewater. In our estimation, hospital wastewater constitutes approximately $0.2 \%$ of both WWTPs' daily inflow. The release of hospital-associated clones of $E$. faecium to the environment was observed also by others $[24,28,35,36]$. In our study, isolates belonging to the major nosocomial HiRECC (formerly named CC17) constituted altogether $24.6 \%$ of all isolates of E. faecium subjected to typing, and were present at all sampling sites. These isolates, apart from their inclusion into the HiRECC by MLST, demonstrated several other phenotypic and genotypic features typical for nosocomial $E$. faecium, i.e. they were resistant to ciprofloxacin and ampicillin, in vast majority showed MDR phenotype, and carried several resistance determinants, associated both with mutations of chromosomal genes ( $g y r A$, parC, $p b p 5)$ and, in the case of aminoglycoside and tetracycline resistance, with gene acquisition. Plasmids likely played an important role in the later process, as some plasmid genes, such as rep $2_{\mathrm{pRE} 25}$, rep $17_{\mathrm{pRUM}}$ and rep18 ${ }_{\mathrm{pEF} 418}$, and TAS genes axe-txe and $\omega-\varepsilon-\zeta$ were significantly more abundant in isolates associated with HiRECC than among the remaining isolates. As yet, the knowledge of distribution of plasmid-associated genes in populations of E. faecium, especially in the context of their clonal composition, remains limited. A study on 93 isolates of different geographical origins and from various sites showed an over-representation of rep $17_{\mathrm{pRUM}}$ and rep $p_{\mathrm{pMG} 1}$ among nosocomial $E$. faecium, while, in contrast to our observations, rep18 pEF418 was not detected [37]. Moreover, we

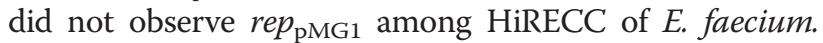
These differences may be due to a high prevalence of VRE (58 isolates) among 93 isolates studied by Rosvoll et al. what may explain differences in the plasmid content. The same study also reported the co-localization of $\omega-\varepsilon-\zeta$ with rep $2_{\mathrm{pRE} 25}$ and axe-txe with rep17 $7_{\mathrm{pRUM}}$ on the same plasmids, in concordance with our findings, showing a frequent joint occurrence of these pairs of genes. Another study, performed on 99 invasive isolates from Norway, mostly of HLGR phenotype, showed a significantly higher prevalence of rep $2_{\mathrm{PRE} 25}$ and rep1 $17_{\mathrm{pRUM}}$ among the major nosocomial HiRECC [38]. This study as well some others $[24,39]$ also demonstrated a common presence of rep $_{\mathrm{pLG1}}$ among E. faecium from hospital settings and in animals. Our findings indicate that this type of replicon is even more ubiquitous in E. faecium than previously reported. All rep genes mentioned above are typically associated with plasmids carrying various antimicrobial resistance genes [39,40], GenBank accession number AF408195. In addition to genes determining antimicrobial resistance and genes associated with MGE, isolates of nosocomial HiRECC analyzed in our study carried such molecular markers as IS16 and the esp gene together with the int $A$ gene characteristic for ICEEfm [41,42]. Another pathogenicity factor, the $f m s 19$ gene of the pilin gene cluster 4 (PGC4) showed increased prevalence among these isolates. Similar observation was made for a representative collection of $433 \mathrm{E}$. faecium isolates from various sources [43].

In a study that followed enterococci in a continuum from hospital and retirement home wastewaters through a WWTP to a river, a gradual decrease in the proportion of $E$. faecium isolates representing hospital-associated STs was observed, likely due to the "dilution" of HiRECC representatives by more diverse and less drug-resistant strains originating from the community [28]. Because in our study only selected representatives of obtained isolates were investigated, it is not possible to determine precise tendencies in their frequency from the WWTP influent to effluent and water, however, resistant enterococci, both HiRECC and non-HiRECC, are clearly able to survive the treatment process, what results in their release into marine and river waters. Moreover, using an additional typing method, MLVA, we were able to find isolates with the same characteristics in the effluent of WWTP and its marine outfall, suggesting ability of such clones to survive in the environment for at least some time. It seems plausible that hospital resistant clones 
accumulate several determinants that may promote their survival not only in the hospital settings but also in the environment. Such features would include resistance to disinfectants and ultraviolet light, additional metabolic pathways and ability to form biofilms. Moreover, determinants of some of the mentioned adaptation factors are found co-resident in plasmids harboring resistance genes, suggesting co-selection. For example, pLG1-type plasmids of E. faecium carry not only resistance determinants against aminoglycosides, glycopeptides and macrolides but also pili genes and carbon uptake-utilization genes [38,39]. Pheromone-responsive plasmids of E. faecalis apart from resistance to aminoglycosides, glycopeptides, penicillins and macrolides may encode bacteriocins, additional pili and UV-resistance determinants [40]. Thus, nosocomial HiRECCs, released by WWTPs, are equipped in whole sets of genes with various adaptive benefits and often located within MGE. It was also demonstrated that MGEs can be transferred in a WWTP [44], further underling the importance of threat posed by such organisms. There is a selection pressure for survival of resistant strains and their tranconjugants due to release of antibiotics to the environment, especially in the hospital effluents [45], and even sub-inhibitory concentrations may be effective in selection for resistance [46].

\section{Conclusions}

This study describes the species composition, resistance profiles and clonal relationships of enterococci isolated from WWTPs located in Gdansk, their marine outfalls to the Gulf of Gdansk and from Vistula River. It was observed that these WWTPs release enterococcal strains resistant to various antimicrobial compounds to the recipient water environment. Molecular analyses revealed the presence of clones associated with nosocomial HiRECCs, and, in the case of E. faecium isolates of lineages 17, 18 and 78 of former CC17 abundant in resistance determinants, MGE genes and pathogenicity factors. The presence of HiRECCs in wastewaters and marine/river environment highlights the need for further detailed analyses to better understand the survival and spread of drug-resistant strains in water ecosystems, and to elucidate the ways to curb such dissemination.

\section{Methods}

\section{Acquisition of samples and isolation of enterococci}

Once a month in April, June, August and October in 2011 of the flow proportioned composited samples of wastewater were taken from two local WWTPs: Gdansk-Wschod from influent (W-INF), effluent (W-EFF), and wastewater from activated sludge bioreactor (W-BR) and from Gdynia-Debogorze effluent (D-EFF). The two WWTPs treat sewage from approximately 920000 inhabitants (for details see Figure 1). In the same period of time and with the same frequency marine outfalls of those WWTPs (W-MOut and D-MOut, respectively) as well as Vistula River mouth were also sampled for isolation of enterococci. Marine samples were taken at the depth of approximately one meter below the surface once a month in April, June, August and October of 2011. Location of sampling points and their characteristics are provided in Figure 1. Enterococci were detected using the membrane filtration method. To this end, appropriate dilutions of analyzed samples were filtered in duplicate through $0.45 \mu \mathrm{m}$ cellulose-acetate filters (EMD Millipore Corporation, Billerica, MA, USA), which were then placed on Enterococcus selective agar (Merck, Darmstadt, Germany) and incubated at $37^{\circ} \mathrm{C}$ for $48 \mathrm{~h}$ (ISO 78992:2000). Dark red or maroon colonies were considered presumptive enterococci. For further investigations, representative isolates were taken from membranes presenting from 20 to 50 typical colonies and stored in nutrient broth supplemented with $15 \%$ glycerol at $-80^{\circ} \mathrm{C}$.

\section{Species identification, DNA isolation, susceptibility testing} and statistical analysis

The species identification and drug susceptibility of presumptive enterococci were determined by the Phoenix ${ }^{\mathrm{Tn}}$ Automated Microbiology System (BD, New Jersey, USA) according to the manufacturer's instructions. Since it is not possible to distinguish $E$. casseliflavus and E. gallinarum using this system, the classification: $E$. casseliflavus/gallinarum was used. The susceptibility tests, based on microdilution, were carried out for 11 antimicrobial agents: gentamicin (GM), streptomycin (ST), ampicillin (AM), daptomycin (DAP), vancomycin (VA), teicoplanin (TEC), linezolid (LZD), fluoroquinolones (ciprofloxacin CIP, levofloxacin - LVX), tetracycline (TE), erythromycin (E) and quinupristin-dalfopristin (SYN) (E. faecium only). Obtained minimal inhibitory concentrations (MIC) were evaluated according to the guidelines of Clinical and Laboratory Standards Institute [47]. Isolates were defined as multidrug-resistant (MDR) when they showed resistance to three or more compounds tested [48]. Bacterial DNA was purified using the Genomic DNA Prep Plus kit following the manufacturer's instructions (A\&A Biotechnology, Gdynia, Poland). Differences in distributions were evaluated using the $x^{2}$ test, with the $\mathrm{p}$ values $<0.05$ considered significant.

\section{MLST and MLVA of E. faecium}

MLST for E. faecium was performed by sequencing of seven house-keeping genes as described by Homan et al. [49]. The allele numbers and STs were assigned with the use of Internet database http://efaecium.mlst.net/ $\left(5^{\text {th }}\right.$ July 2013, date last accessed). Novel alleles and allelic profiles were submitted to the database. MLST data were analyzed with Sequence Type Analysis and Recombinational Tests 
(START) software [50] and the eBURST analysis [51] was used to elucidate the relationships of STs with known CCs, using the comparative eBURST option available at http://eburst.mlst.net/v3/enter_data/comparative/ $\left(5^{\text {th }}\right.$ July 2013, date last accessed). Further inclusion of E. faecium STs into specific CCs and lineages was performed following other studies $[9,24]$. MLVA was performed as described by others [52].

\section{Detection and analysis of genes associated with virulence, antimicrobial resistance and MGE in E. faecium}

The full list of primers used for gene detection and sequencing is provided in Additional file 1: Table S1. PCRbased detection of IS16, virulence-associated genes ( $f m s 21$, fms17, fms 5 and fms19, representing each of four pilin gene clusters in E. faecium, and the $\operatorname{ssp}_{\mathrm{Efm}}$ gene), genes determining resistance to tetracycline $\{\operatorname{tet}(\mathrm{M}), \operatorname{tet}(\mathrm{O}), \operatorname{tet}(\mathrm{L})$, tet(S)\}, HLGR (aac(6')-Ie-aph(2"), HLSR (ant(6')-Ia) and genes specific for MGE, such as intA of ICEEfm1, int of Tn916 transposon, tnd $X$ of Tn5397 transposon, enterococcal plasmid replication genes rep $_{\text {pIP501 }}$, rep $2_{\text {pRE25, }}$ rep $17_{\mathrm{pRUM}}, r e p 18_{\mathrm{pEF} 418}, r e p_{\mathrm{pMG} 1}, r e p_{\mathrm{pLG} 1}$ and TAS genes axe-txe, $\omega-\varepsilon-\zeta$, relBE was performed as described in other studies [13,41,53-59], following the conditions described herein. Previously characterized clinical isolates of Streptococcus agalactiae, E. faecium and E. faecalis harbouring

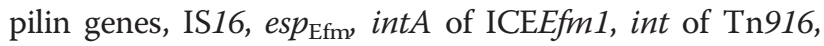
$\operatorname{tnd} X$ of $\operatorname{Tn} 5397, \operatorname{tet}(\mathrm{M}), \operatorname{tet}(\mathrm{O}), \operatorname{tet}(\mathrm{L}), \operatorname{tet}(\mathrm{S}), \operatorname{aac}\left(6^{\prime}\right)-I e-$ $\operatorname{aph}\left(2^{\prime \prime}\right)$, ant $\left(6^{\prime}\right)-I a, r e p 1_{\mathrm{pIP} 501}$, rep $2_{\mathrm{pRE} 25}, \omega-\varepsilon-\zeta[13,60,61]$ served as positive controls. In cases when positive controls were not available (rep18 pEF418, rep $_{\mathrm{pMG1}}, r e p_{\mathrm{pLG}}$, axe-txe, relBE), a few randomly selected PCR products were verified by sequencing and served further as controls. Ampicillin-resistance determinant, the $p b p 5$ gene was analysed by sequencing of the part encoding C-terminal transpeptidase domain in PBP5 [62]. New sequence variants, $p b p 5$-24 to $p b p 5$-29 alleles were submitted to the GenBank (acc. numbers KC594860-KC594865, respectively). The quinolone-determining regions (QRDR) in the gyrA and parC genes were sequenced and analysed as described by others [63].

\section{Additional file}

Additional file 1: Table S1. Primers used in the study for PCR and sequencing.

\section{Competing interest}

The authors declare that they have no competing interest.

\section{Authors' contributions}

ES participated in the study design, performed experimental work and participated in the manuscript preparation; AL designed the study, performed experimental work and participated in the manuscript preparation. Both authors read and approved the final manuscript.

\section{Acknowledgements}

We thank Rob Willems and Janetta Top for assigning new alleles, new STs and MTs. This publication made use of the Enterococcus faecium MLST website (http://efaecium.mlst.net/) which is hosted at Imperial College of the University of Oxford and funded by the Wellcome Trust. This work was supported by project N N305 461139 from the Narodowe Centrum Nauki (NCN).

\section{Author details}

${ }^{1}$ National Medicines Institute, ul. Chelmska 30/34, Warsaw 00-725, Poland. ${ }^{2}$ Gdansk University of Technology, ul. G. Narutowicza 11/12, Gdansk 80-952, Poland.

Received: 5 September 2013 Accepted: 27 February 2014

Published: 14 March 2014

\section{References}

1. Aarestrup FM, Butaye P, Witte W: Nonhuman reservoirs of Enterococci. In American Society for Microbiology. Edited by Gilmore MS, Clewell DB, Courvalin P, Dunny GM, Murray BE, Rice LB. Washington DC: The Enterococci: pathogenesis, molecular biology and antibiotic resistance; 2002.

2. Tendolkar PM, Baghdayan AS, Shankar N: Pathogenic enterococci: new developments in the $21^{\text {st }}$ century. Cell Mol Life Sci 2003, 60:2622-2636.

3. Sood S, Malhotra M, Das BK, Kapil A: Enterococcal infections \& antimicrobial resistance. Indian J Med Res 2008, 128:111-121.

4. Sydnor ER, Perl TM: Hospital epidemiology and infection control in acute-care settings. Clin Microbiol Rev 2011, 24:141-173.

5. European Centre for Disease Prevention and Control: Annual Epidemiological Report, Reporting on 2010 surveillance data and 2011 epidemic intelligence data. Stockholm: ECDC; 2012:2013.

6. Hidron Al, Edwards JR, Patel J, Horan TC, Sievert DM, Pollock DA, Fridkin SK, National Healthcare Safety Network Team; Participating National Healthcare Safety Network Facilities: NHSN annual update: antimicrobial-resistant pathogens associated with healthcare-associated infections: annual summary of data reported to the National Healthcare Safety Network at the Centers for Disease Control and Prevention, 2006-2007. Infect Control Hosp Epidemiol 2008, 29:996-1011.

7. De Kraker ME, Jarlier V, Monen JC, Heuer OE, van de Sande N, Grundmann $\mathrm{H}$ : The changing epidemiology of bacteraemias in Europe: trends from the European Antimicrobial Resistance Surveillance System. Clin Microbiol Infect 2012. doi:10.1111/1469-0691.

8. Leavis $\mathrm{HL}$, Bonten MJ, Willems RJ: Identification of high-risk enterococcal clonal complexes: global dispersion and antibiotic resistance. Curr Opin Microbiol 2006, 9:454-460.

9. Willems RJL, Top J, van Schaik W, Leavis H, Bonten M, Sirén J, Hanage WP, Corander J: Restricted gene flow among hospital subpopulations of Enterococcus faecium. mBio 2012, 3:e00151-12.

10. Hegstad K, Mikalsen T, Coque TM, Werner G, Sundsfjord A: Mobile genetic elements and their contribution to the emergence of antimicrobial resistant Enterococcus faecalis and Enterococcus faecium. Clin Microbiol Infect 2010, 16:541-554.

11. Shepard BD, Gilmore MS: Antibiotic-resistant enterococci: the mechanisms and dynamics of drug introduction and resistance. Microbes Infect 2002, 4:215-224.

12. Bonten MJ, Willems R, Weinstein RA: Vancomycin-resistant enterococci: why are they here, and where do they come from? Lancet Infect Dis 2001, 1:314-325.

13. Sadowy E, Sieńko A, Gawryszewska I, Bojarska A, Malinowska K, Hryniewicz W: High abundance and diversity of antimicrobial resistance determinants among early vancomycin-resistant Enterococcus faecium in Poland. Eur J Clin Microbiol Infect Dis 2013, 32:1193-1203.

14. Willems RJ, Homan W, Top J, van Santen-Verheuvel M, Tribe D, Manzioros X, Gaillard C, Vandenbroucke-Grauls CM, Mascini EM, van Kregten E, van Embden JD, Bonten MJ: Variant esp gene as a marker of a distinct genetic lineage of vancomycin-resistant Enterococcus faecium spreading in hospitals. Lancet 2001, 357:853-855.

15. Sillanpää J, Nallapareddy SR, Prakash VP, Qin X, Höök M, Weinstock GM, Murray BE: Identification and phenotypic characterization of a second collagen adhesin, Scm, and genome-based identification and analysis of 13 other predicted MSCRAMMs, including four distinct pilus loci, in Enterococcus faecium. Microbiology 2008, 154:3199-3211. 
16. Galloway-Peña JR, Nallapareddy SR, Arias CA, Eliopoulos GM, Murray BE: Analysis of clonality and antibiotic resistance among early clinical isolates of Enterococcus faecium in the United States. J Infect Dis 2009, 200:1566-1573.

17. Top J, Willems R, Bonten M: Emergence of CC17 Enterococcus faecium: from commensal to hospital-adapted pathogen. FEMS Immunol Med Microbiol 2008, 52:297-308.

18. Martins da Costa P, Vaz-Pires P, Bernardo F: Antimicrobial resistance in Enterococcus spp. isolated in inflow, effluent and sludge from municipal sewage water treatment plants. Water Res 2006, 40:1735-1740.

19. Reinthaler FF, Posch J, Feierl G, Wust G, Haas D, Ruckenbauer G, Mascher F, Marth E: Antibiotic resistance of Escherichia coli in sewage and sludge. Water Res 2003, 37:1685-1690.

20. Luczkiewicz A, Fudala-Ksiazek S, Jankowska K, Olanczuk-Neyman K. Antimicrobial resistance of fecal indicators in municipal wastewater treatment plant. Water Res 2010, 44:5089-5097.

21. Dulfour AP, Ballentine RK: Ambient water quality criteria for bacteria-1986 EPA 440/5-84-002. Washington, DC: US Environmental Protection Agency; 1986.

22. Ferreira da Silva M, Tiago I, Veríssimo A, Boaventura RA, Nunes OC, Manaia CM: Antimicrobial resistance patterns in Enterobacteriaceae isolated from an urban wastewater treatment plant. FEMS Microbiol Ecol 2007, 60:166-176.

23. DIRECTIVE 2006/7/EC of the European Parliament and of the Council, 15 February 2006, concerning the management of bathing water quality and repealing Directive 76/160/EEC: http://eur-lex.europa.eu/LexUriServ/ LexUriServ.do?uri=OJ:L:2006:064:0037:0051:EN:PDF.

24. Freitas AR, Novais C, Ruiz-Garbajosa P, Coque TM, Peixe L: Dispersion of multidrug-resistant Enterococcus faecium isolates belonging to major clonal complexes in different Portuguese settings. Appl Environ Microbiol 2009, 75:4904-4908.

25. Poeta P, Costa D, Igrejas G, Sáenz Y, Zarazaga M, Rodrigues J, Torres C: Polymorphisms of the $p b p 5$ gene and correlation with ampicillin resistance in Enterococcus faecium isolates of animal origin. $J$ Med Microbiol 2007, 56:236-240

26. Kühn I, Iversen A, Burman LG, Olsson-Liljequist B, Franklin A, Finn M, Aarestrup F, Seyfarth AM, Blanch AR, Vilanova X, Taylor H, Caplin J, Moreno MA, Dominguez L, Herrero IA, Möllby R: Comparison of enterococcal populations in animals, humans, and the environment - a European study. Int J Food Microbiol 2003, 88:133-145.

27. Lanthier M, Scott A, Lapen DR, Zhang Y, Topp E: Frequency of virulence genes and antibiotic resistances in Enterococcus spp. isolates from wastewater and feces of domesticated mammals and birds, and wildlife. Can J Microbiol 2010, 56:715-729.

28. Leclercq R, Oberlé K, Galopin S, Cattoir V, Budzinski H, Petit F: Changes in enterococcal populations and related antibiotic resistance along a medical center-wastewater treatment plant-river continuum. Appl Environ Microbiol 2013, 79:2428-2434

29. Thevenon F, Regier N, Benagli C, Tonolla M, Adatte T, Wildi W, Poté J: Characterization of fecal indicator bacteria in sediments cores from the largest freshwater lake of Western Europe (Lake Geneva, Switzerland). Ecotoxicol Environ Safety 2012, 78:50-56.

30. Bonilla TD, Nowosielski K, Esiobu N, McCorquodale DS, Rogerson A: Species assemblages of Enterococcus indicate potential sources of fecal bacteria at a south Florida recreational beach. Mar Pollut Bull 2006, 52:807-810

31. Wang JT, Chang SC, Wang HY, Chen PC, Shiau YR, Lauderdale TL, TSAR Hospitals: High rates of multidrug resistance in Enterococcus faecalis and E. faecium isolated from inpatients and outpatients in Taiwan. Diagn Microbiol Infect Dis 2013, 75:406-411.

32. Lanthier M, Scott A, Zhang Y, Cloutier M, Durie D, Henderson VC, Wilkes G, Lapen DR, Topp E: Distribution of selected virulence genes and antibiotic resistance in Enterococcus species isolated from the South Nation River drainage basin, Ontario, Canada. J Appl Microbiol 2011, 110:407-421.

33. Kuch A, Willems RJ, Werner G, Coque TM, Hammerum AM, Sundsfjord A, Klare I, Ruiz-Garbajosa P, Simonsen GS, van Luit-Asbroek M, Hryniewicz W, Sadowy E: Insight into antimicrobial susceptibility and population structure of contemporary human Enterococcus faecalis isolates from Europe. J Antimicrob Chemother 2012, 67:551-558.

34. Novais C, Coque TM, Ferreira H, Sousa JC, Peixe L: Environmental contamination with vancomycin-resistant enterococci from hospital sewage in Portugal. Appl Environ Microbiol 2005, 71:3364-3368.
35. Iversen A, Kühn I, Rahman M, Franklin A, Burman LG, Olsson-Liljequist B, Torell E, Möllby R: Evidence for transmission between humans and the environment of a nosocomial strain of Enterococcus faecium. Environ Microbiol 2004, 6:55-59

36. Rathnayake I, Hargreaves M, Huygens F: SNP diversity of Enterococcus faecalis and Enterococcus faecium in a South East Queensland waterway, Australia, and associated antibiotic resistance gene profiles. BMC Microbiol 2011, 11:201.

37. Rosvoll TC, Pedersen T, Sletvold H, Johnsen PJ, Sollid JE, Simonsen GS, Jensen LB, Nielsen KM, Sundsfjord A: PCR-based plasmid typing in Enterococcus faecium strains reveals widely distributed pRE25-, pRUM-, pIP501- and pHT-related replicons associated with glycopeptide resistance and stabilizing toxin-antitoxin systems. FEMS Immunol Med Microbiol 2010, 58:254-268.

38. Rosvoll TC, Lindstad BL, Lunde TM, Hegstad K, Aasnaes B, Hammerum AM, Lester $\mathrm{CH}$, Simonsen GS, Sundsfjord A, Pedersen T: Increased high-level gentamicin resistance in invasive Enterococcus faecium is associated with aac $\left(6^{\prime}\right)$ le-aph $\left(2^{\prime \prime}\right)$ la-encoding transferable megaplasmids hosted by major hospital-adapted lineages. FEMS Immunol Med Microbiol 2012, 66:166-176.

39. Laverde Gomez JA, van Schaik W, Freitas AR, Coque TM, Weaver KE, Francia MV, Witte W, Werner G: A multiresistance megaplasmid pLG1 bearing a hyl $_{\text {Efm }}$ genomic island in hospital Enterococcus faecium isolates. Int J Med Microbiol 2011, 301:165-175.

40. Coque TM: Evolutionary biology of pathogenic enterococci. In Evolutionary Biology of Bacterial and Fungal Pathogens, Coque TM. Edited by Baquero F, Nombela C, Cassell GH, Gutierrez JA. Washington, DC: ASM Press:501-523.

41. Werner G, Fleige C, Geringer U, van Schaik W, Klare I, Witte W: IS element IS16 as a molecular screening tool to identify hospital-associated strains of Enterococcus faecium. BMC Infect Dis 2011, 11:80.

42. Top J, Sinnige JC, Majoor EA, Bonten MJ, Willems RJ, van Schaik W: The recombinase IntA is required for excision of esp-containing ICEEfm 1 in Enterococcus faecium. J Bacteriol 2011, 193:1003-1006.

43. Sillanpää J, Prakash VP, Nallapareddy SR, Murray BE: Distribution of genes encoding MSCRAMMs and Pili in clinical and natural populations of Enterococcus faecium. J Clin Microbiol 2009, 47:896-901.

44. Marcinek H, Wirth R, Muscholl-Silberhorn A, Gauer M: Enterococcus faecalis gene transfer under natural conditions in municipal sewage water treatment plants. Appl Environ Microbiol 1998, 64:626-632.

45. Kümmerer K: Significance of antibiotics in the environment. $J$ Antimicrob Chemother 2003, 52:5-7.

46. Liu A, Fong A, Becket E, Yuan J, Tamae C, Medrano L, Maiz M, Wahba C, Lee C, Lee K, Tran KP, Yang H, Hoffman RM, Salih A, Miller JHP: Selective advantage of resistant strains at trace levels of antibiotics: a simple and ultrasensitive color test for detection of antibiotics and genotoxic agents. Antimicrob Agents Chemother 2011, 55:1204-1210.

47. Clinical and Laboratory Standards Institute: Performance standards for antimicrobial susceptibility testing; $21^{\text {st }}$ informational supplement. Wayne: CLSI; 2011. PA M100-S20.

48. Magiorakos AP, Srinivasan A, Carey RB, Carmeli Y, Falagas ME, Giske CG, Harbarth S, Hindler JF, Kahlmeter G, Olsson-Liljequist B, Paterson DL, Rice LB, Stelling J, Struelens MJ, Vatopoulos A, Weber JT, Monnet DL: Multidrug-resistant, extensively drug-resistant and pandrug-resistant bacteria: an international expert proposal for interim standard definitions for acquired resistance. Clin Microbiol Infect 2012, 18:268-281.

49. Homan WL, Tribe D, Poznanski S, Li M, Hogg G, Spalburg E, Van Embden JD Willems RJ: Multilocus sequence typing scheme for Enterococcus faecium. J Clin Microbiol 2002, 40:1963-1971.

50. Jolley KA, Feil EJ, Chan MS, Maiden MC: Sequence type analysis and recombinational tests (START). Bioinformatics 2001, 17:1230-1231.

51. Feil EJ, Li BC, Aanensen DM, Hanage WP, Spratt BG: eBURST: inferring patterns of evolutionary descent among clusters of related bacterial genotypes from multilocus sequence typing data. J Bacteriol 2004, 186:1518-1530.

52. Top J, Banga1 NMI, Hayes R, Willems RJ, Bonten MJM, Hayden MK: Comparison of multiple-locus variable-number tandem repeat analysis and pulsed-field gel electrophoresis in a setting of polyclonal endemicity of vancomycin-resistant Enterococcus faecium. Clin Microbiol Infect 2008, 14:363-369.

53. Vankerckhoven V, Van Autgaerden T, Vael C, Lammens C, Chapelle S, Rossi $R$, Jabes D, Goossens H: Development of a multiplex PCR for the 
detection of asa1, gelE, cylA, esp and hyl genes in enterococci and survey for virulence determinants among European hospital isolates of Enterococcus faecium. J Clin Microbiol 2004, 42:4473-4479.

54. Doherty N, Trzcinski K, Pickerill P, Zawadzki P, Dowson CG: Genetic diversity of the tet $(\mathrm{M})$ gene in tetracycline-resistant clonal lineages of Streptococcus pneumoniae. Antimicrob Agents Chemother 2000, 44:2979-2984.

55. Trzcinski K, Cooper BS, Hryniewicz W, Dowson CG: Expression of resistance to tetracyclines in strains of methicillin-resistant Staphylococcus aureus. J Antimicrob Chemother 2000, 45:763-770.

56. Leelaporn A, Yodkamol K, Waywa D, Pattanachaiwit S: A novel structure of Tn4001-truncated element, type $\mathrm{V}$, in clinical enterococcal isolates and multiplex PCR for detecting aminoglycoside resistance genes. Int J Antimicrob Agents 2008, 31:250-254

57. Agers $\varnothing$ Y, Pedersen AG, Aarestrup FM: Identification of Tn5397-like and Tn916-like transposons and diversity of the tetracycline resistance gene tet( $M$ ) in enterococci from humans, pigs and poultry. J Antimicrob Chemother 2006, 57:832-839.

58. Jensen LB, Garcia Migura L, Valenzuela AJ, Løhr M, Hasman H, Aarestrup FM: A classification system for plasmids from enterococci and other gram-positive bacteria. J Microbiol Methods 2010, 80:25-43

59. Moritz EM, Hergenrother PJ: Toxin-antitoxin systems are ubiquitous and plasmid-encoded in vancomycin-resistant enterococci. Proc Natl Acad Sci U S A 2007, 104:311-316.

60. Wardal E, Gawryszewska I, Hryniewicz W, Sadowy E: Abundance and diversity of plasmid-associated genes among clinical isolates of Enterococcus faecalis. Plasmid 2013, 70:329-342.

61. Sadowy E, Matynia B, Hryniewicz W: Population structure, virulence factors and resistance determinants of invasive, non-invasive and colonizing Streptococcus agalactiae in Poland. J Antimicrob Chemother 2010, 65:1907-1914

62. Hsieh SE, Hsu LL, Hsu WH, Chen CY, Chen HJ, Liao CT: Importance of amino acid alterations and expression of penicillin-binding protein 5 to ampicillin resistance of Enterococcus faecium in Taiwan. Int J Antimicrob Agents 2006, 28:514-519.

63. el Amin NA, Jalal S, Wretlind B: Alterations in GyrA and ParC associated with fluoroquinolone resistance in Enterococcus faecium. Antimicrob Agents Chemother 1999, 43:947-949.

doi:10.1186/1471-2180-14-66

Cite this article as: Sadowy and Luczkiewicz: Drug-resistant and hospital-associated Enterococcus faecium from wastewater, riverine estuary and anthropogenically impacted marine catchment basin. BMC Microbiology 2014 14:66.

\section{Submit your next manuscript to BioMed Central and take full advantage of:}

- Convenient online submission

- Thorough peer review

- No space constraints or color figure charges

- Immediate publication on acceptance

- Inclusion in PubMed, CAS, Scopus and Google Scholar

- Research which is freely available for redistribution

Submit your manuscript at www.biomedcentral.com/submit
( Biomed Central 